\title{
The Influence of Personality Trait on the Academic Performance of Secondary School Students in Cross River State, Nigeria.
}

\author{
${ }^{1}$ Eyong, Emmanuel Ikpi, ${ }^{2}$ David, Bassey Enya, ${ }^{3}$ Umoh, Augustus Johnny \\ ${ }^{I}$ Department of Education Foundation Guidance and Counselling University of Calabar \\ ${ }^{2}$ Department of Educational Foundations, Guidance and Counseling, University of Calabar, Calabar. \\ ${ }^{3}$ Department of Curriculum and Instructional Technology Cross River University of Technology Calabar
}

\begin{abstract}
This study investigated the influence of personality traits on academy achievements of secondary school students in Cross River State. Two research questions and hypotheses were tested at .05 levels of significance to guide the conduct of the study. The research design used was casual-comparative or ex-post facto. The population of the study consisted of 13, 838 SSI students in all 239 public secondary schools throughout Cross Rivers State. A total of 7 LGAs were randomly drawn out of 23. Then 20 schools were randomly selected, from which a sample of 8530 SSI students was finally drawn. The instrument adapted for the study was the 44-item standardized questionnaire known as the big five personality model by Robert McCrae and Paul Costa (1999). This was validated by expert in the field of measurement and evaluation; the reliability was established using the test re-test method and the reliability coefficient was calculated using Pearson moment correlation coefficient $(r)$ and the reliability indices obtained were, 0.68 , and 0.62 respectively for conscientiousness and agreeableness. The data collected were analyzed using the mean $(x)$ and standard deviation (SD) to answer the research question. The independent sample t- test was used to test the hypothesis in order to determine whether there is a significance difference between the means two independent groups being compared for each trait. A significant difference was found between the achievements of students with high level of conscientiousness and agreeableness, and those with low levels of the traits. Based on the findings, the following recommendations were made. Parents and teacher should encourage their children/wards or students to set clear goals, and ensure that they are disciplined and careful to consistently achieve them. Incentives should be arranged to accompany success to encourage continuous positive performance. This will serve as positive reinforcement. Teacher should endeavor to be close to their students through interaction outside the classroom. Government too can encourage more sponsorship programs to encourage the indigent but conscientious students further their education. Also Neurotic tendencies such as anger, depression, anxiety, and a low self esteem should be discouraged in students at all levels both at home and in the school. Parent should inculcate self confidence in their children by affirming them whenever they do the right thing and correct in love whenever they do wrong. Teachers and counseling psychologists should help them have a positive self esteem through affirmation. This is why guidance and counseling units must be encouraged in all school where this is not the case, especially in the rural areas.
\end{abstract}

Keywords: Personality, Trait, Academic Performance and Students.

\section{Introduction}

Academic achievement is a major issue among students, teachers, parents, school administrators, and the community at large. Attempts have been made by researchers to unravel the complexities surrounding academic achievement. Psychologists have put forward a lot of reasons why these disparities in achievement exist. A lot of attention had been paid to external factors such as type of school, teaching methods, school location, instructional materials, teachers experience, and so on (WAEC, 2005). Many spend lots of money in order to secure good schools either for their children or themselves and those who can afford it even invest on education abroad as they believe this will enhance achievement, and which in turn gives an added advantage in terms of securing gainful employment. Opinions vary as to why some students excel academically while others appear to be underachievers. Many psychologists have consistently attempted to identify the major predictors of individual academic achievement. Factors such as intelligence, self concept, gender, study habit, maturation, home background, amongst others, just to mention a few, have been extensively explored as being responsible for academic achievement, especially in secondary school students. Other factors that have been researched into in the past include: child rearing patterns, peer group influence, socio-economic background and learning environment. Another major factor that is believed to be responsible for academic achievement in students is their personality traits. How true is this? Traits Theorists have tried to identify the major traits that characterize personality. Notable among these are Sigmund Freud in the early 1900's, Gordon All port (1961), Cattell (1967), Hans Eysenck (1985) Feldman (1994), McCrae and Costa (1987) and 
a host of others. Personality has been defined in many ways by many psychologists who wrote on the concept. According to Feldman (1994) in Daminabo (2008), Personality is the sum total of the characteristics that differentiates people, or the stability of a person's behavior across different situations. In other words it means those qualities the individual is noted for. Traits on the other hand are "enduring dimensions of personality characteristics which differentiates people from one another" (Colman, 2003 in Daminabo 2008). Traits are therefore the sum total of stable characteristics in a person across different times and situations, which make him or her unique or distinct from others. This agrees with the definition by Mischel 1981, (in Agbakwuru, 2000: 23) which refer to personality traits as consistent differences between the behaviors characteristic of two or more people. It is also defined as "any distinguishable, relatively enduring way in which one individual varies from another" (Guliford, 1959 in Agbakwuru 2000: 23).However, there has been an increasing interest in the big five personality traits and the role they play as regards academic achievement of students. Of particular interest is the role that these traits play in the academic achievement of secondary school students. These traits, popularly known as the 'Big Five' include conscientiousness, agreeableness, openness to experience, extraversion and locus of control. The acronym CAOEL is used to describe them. These personality traits affect academic achievement in students, either positively or negatively. There have been reported incidences of underachievement in secondary school students as evidenced by poor performances in WAEC results which, over the years have been the standard measurement of academic achievement. According to statistics in Daily Champion of 4th April 2010 analyzing the results of the 2010 May/June West African Senior School Certificate Examination (WASSCE), only 337,071 candidates, representing 24.94 per cent, out of the 1,351,557 candidates who wrote the examination obtained five effective credits and above. Effective credits simply means that the subjects' combinations include English Language and Mathematics, which are compulsory for admission into the universities in Nigeria. The results show a marginal one per cent lower than last year's result. But 77,168 others won't have their results based on reports of examination malpractice. It should be recalled that in the May/June 2009 examination, only 356,981 candidates representing 26 per cent of the 1,373,009 students who sat for the examination obtained five effective credits. Also, the November/December examination meant for private candidates last year recorded a similar poor performance. Out of the 342,433 candidates who took the examination, only 106,413 or 31 per cent had five effective credits, even though the number of candidates is significantly lower. The worst result so far was recorded in the May/June examination of 2012. Out of a total of 1,369,142 candidates that sat for the examination, only a meager 188,442 representing 13.76 per cent obtained five effective credits and above. The truth is that once a candidate fails to obtain the required five effective credits in the first attempt, he or she is bound to retake the examination to make up the deficient subjects. Failure to make up those subjects effectively shuts the candidate out of university admission. It is no longer news that the public school system has collapsed. Consequently, many parents who can afford money to re-register their children take their wards to private schools. The private schools are not necessarily better. This situation has unpleasant implications for the youths and the future of the country. These results have shown a steady drop in achievement and this trend has continued despite efforts by psychologists, educationists and all concerned to effect change. Thus, in a desperate bid to pass by all means, examination malpractice has been encouraged in varying degrees. Many students are not able to defend the result they carry. It is worrisome that a student having seven A's including English and Mathematics can neither make correct sentences in English, nor solve simple algebraic problems.

And so parents, educationists, psychologists, counselors, are all worried at the rate of decline of academic standard. Big Five otherwise known as CAOEL has therefore been explored in order to find possible solutions to the problem of underachievement amongst secondary school students. The acronym CAOEL denotes the traits: conscientiousness, agreeableness, openness, extraversion and locus of control to experience. McCrae and Costa (1980) researched extensively on these traits.

A high score on Conscientiousness shows a student who is self disciplined, careful, thorough, organized and determined. Low scores on this trait portray indiscipline, carelessness, disorganization and indifference. That student who scores highly on this trait is expected to perform excellently well, academically and vice versa.

Agreeableness describes one who is sympathetic, trusting and cooperative. Students with high scores on agreeableness are selfless, flexible and pleasant. Such students work with others easily with little or no friction. Those scoring low on this trait however find it difficult to get along with others. McCrae and Costa 1988 in Daminabo, (2008) noted this to be psychotics, which refers to a person who is skeptical, unsympathetic, uncooperative and rude. Low scores are expected to affect academic achievement negatively.

The researcher is therefore out to examine what influence these personality traits have on the academic achievement of students using JSS3 students who just wrote their junior WAEC some months before. Their scores on the personality traits was compared with their achievement scores in the JSS3 standardized WAEC results, since these traits are not expected to have changed considerably between then and now. 


\section{Theories of Personality}

\section{Theoretical Framework}

Several theories have emerged in a bid to explain why people behave the way they do. Although two factor out of the five factor model of personality is being used for this study, a major theory of personality was reviewed in addition to the trait theories. The following theories were reviewed.

Sigmund Freud's Psychoanalytic Theory

Trait theories of Personality

\section{Sigmund Freud's Psychoanalytic Theory:}

Psychoanalysts believe man's behaviour is triggered mostly by powerful hidden forces within the personality. These forces are shaped by childhood experiences and they play an important role in energizing and directing our everyday behaviour. Sigmund Freud, an Australian physician was the originator of this theory in the early nineties He says much of people's everyday behaviour is motivated by unconscious forces about which they know little. In order to fully understand personality then one need to illuminate and expose what is in the unconscious. According to Freud's model of personality, there are three major components: the id, the ego and the superego, which although are separate components, interact within the individual. The id, which is the raw, untamed, unorganized, uncultured and inherited part of personality whose function is to reduce the tension created by biological drives such as hunger, sex, aggressiveness and irrational impulses. It operates according to the pleasure principle which goal is the immediate reduction of tension and maximization of pleasure. However harsh realities of life prevent the satisfaction of the demands of the pleasure principle in most cases by presenting constraints. The ego acts as buffer and helps cushion the effects of reality. The ego operates according to the reality principle in which instinctual energy is retrained in order to maintain the safety of the individual and help to integrate him into the society. The ego makes decisions controls actions and allows thinking and problem solving of a higher order than the id is capable of. The superego acts the final component, which represents rights and wrongs of society as handed down by one's parents, teachers and other important figures. It becomes part of personality when children learn rights from wrongs and continue to develop as people in the society in which they live begin to incorporate their own standards into them. These are the components of adult personality. Whenever the demands of the id or the super ego threaten to overwhelm the ego, anxiety is the result. Ego defense mechanisms such as regression, denial, repression etc. are therefore used to reduce to reduce anxiety by distorting either thoughts or reality. Although Freud's conception faced a lot of criticisms due to dearth of scientific evidence to support it, nevertheless it had gained a lot of impact in the field of psychology.

Trait theories of Personality

The quest to know why people behave the way they do, has been on, it has attracted so many researches. In order to answer some of these questions, personality psychologists have developed a sophisticated model of personality known as trait theory. (Michel, 1978 in Daminabo, 2008) defined a trait as a "continuous dimension on which individual differences may be arranged quantitatively in terms of the amount of the characteristics the individual has". Chauham, 1978 in Chowdhnry (2006), defined trait as "a property within the individual that accounts for his unique but relatively stable reactions to the environment". Other personality theorists emphasize the role of biological, cognitive and environmental forces in shaping personality. Personality description is not the central goal of these theorists; instead their goal is to explain personality and behavior in terms of their underlying causes.

According to Hockenbugh and Hockenbugh (1997), trait theory of personality is one that focuses on identifying, describing and measuring individual differences. Feldman (1994) said that trait theories do not assume that some people have a trait and others do not; rather they propose that all people have certain trait, but that the degree to which the trait applies to a specific person varies and can be quantified. For instance, a person might be extremely shy, somewhat shy, or not shy at all. Hence a trait is typically described in terms of a range from one extreme to its opposite. The first attempt to identify and describe these characteristics was to develop a system to discover how many types of individuals there are and identify each person's type. The ancient Greek psychologists divided people into four types: this was made popular by Galen, who in his own opinion also spoke of four types of individuals in Lefrancois (1983) they are sanguine (optimistic and happy). Melancholic (Unhappy, depressed). Choleric (violent tempered) the Phlegmatic (apathetic), not really moved to excesses of emotion. Some other prominent trait theorists include the following:

\section{Statement of the problem}

The problem of underachievement has assumed a worrisome dimension in the Nigerian educational system. Desperate to make it anyhow, students have devised various illegal means to succeed in examinations, even when they are not academically competent. And unfortunately, the system has buckled under the pressure. Examination malpractice has risen steadily to become a seemingly untamable monster. It is increasingly 
becoming difficult to equate competence of people with supposed academic performance as represented in their certificates. Many candidates are unable to defend the result they supposedly acquired honorably. And of course this has consistently led to inability to compete effectively in the job market which has become a serious issue. Several factors have been researched into in the past as to the cause of this social malaise, but there seem to be indications that some hidden factors may be responsible that needs unraveling. This desire to see this problem curbed gave rise to this study and the researchers' aim is to see if there is a way in which the big five personality traits can help, especially from the perspective of the analytical and scientific approach of measurement and evaluation.

The researcher has consequently chosen to explore this problem among the JSS 3 students who just wrote their JSS 3 exams not too long ago. This study is therefore aimed at an examination of the influence of personality traits on academic achievement of secondary school students in Cross River Rivers State.

\section{Purpose of the study}

The purpose of the study is therefore to:

1. Find out there is any significant relationship between conscientiousness and students academic achievement.

2. Find out there is any significant relationship between agreeableness and students academic achievement.

\section{Research hypotheses}

The following hypotheses were therefore postulated:

1. There is no significant relationship between conscientiousness and students academic achievement.

2. There is no significant relationship between agreeableness and students academic achievement.

\section{Methodology}

This section deals with the procedure followed in this work in order to realize the set objectives. The following areas were covered:

Research design

Area of study

Population of study

Sample

Sampling technique

Instrument for data collection

Validation of instrument

Reliability of Instrument

Procedure for data collection

Method of data analysis.

\section{Research design}

The research design used in this study is the causal comparative approach, otherwise known as the ex-post facto research design. There will be no attempt to manipulate the variables since an Ex-postfacto design presumes that the data are collected after the events of interest have occurred. Also both the effect(s) and the alleged cause(s) have already occurred and hence are studied in retrospect. According to Fraenkel and Wallen (2000), Causal-comparative research allows researchers to investigate the possibility of a causal relationship among variables that cannot be manipulated as in experimental research. In a causal comparative study two or more groups that are different on a particular variable are compared on another variable. The researcher decided to adopt this design for this study because is an inherent trait among the subjects used for this study.

\section{Area of the study}

Southern Senatorial district is one of the three senatorial district in Cross River State. It is made up of 7 Local Government Areas (CRSG, 2007). These local Governments are: Biase, Akamkpa, Odukpani, Calabar South, Calabar Municipality, Akpabuyo, and Bakassi. It lies within latitude 5.250 and $8.00 \mathrm{~N}$ and Longitude 70 $50^{\prime}$ and 9.300 E. It has a land mass of 7, 300 square kilometres, and is bounded by Akwa Ibom State to the South, Yakurr Local Government Areas to the North, Abi Local Government Areas to the East and the Republic of Cameroon to the West. It has the largest forest area in the state and a very fertile land, watered by many rivers, streams and springs, the people are mostly agrarian. The major occupation of the people is fishing, farming and mining of stone and gravels. The researcher chooses this area because he resides and works within the area. 


\section{Population of the study}

The population of the study comprises of all 13,838 senior secondary School one (SSI) students in the 7 Local Government Areas of Southern Senatorial district of Cross Rivers State, according to the information obtained from the Cross Rivers State Post Primary Schools Boards 2011.

\section{Sample}

The sample size of 830 representing 6 percent $(6 \%)$ of the total estimated population of the thirteen thousand eight hundred and thirty eight students from ten (10) Public Schools in Southern Senatorial District of Cross River State. The sample will consist of both male and female students. The sample distribution of schools is illustrated as follows:

\begin{tabular}{lll} 
TABLE 1 Sample Distribution of Schools in South-South Senatorial District of Cross River State \\
\hline S/N & \multicolumn{1}{c}{ NAME OF SCHOOLS } & TOTAL NO. OF STUDENTS \\
\hline 1 & Community Secondary School, Akamkpa & \\
2 & Community Secondary School, Akpabuyo & 83 \\
3 & Community Secondary School, Bakassi & 83 \\
4 & Community Secondary School, Odukpani & 83 \\
5 & St. Patrick's Technical College. Calabar & 83 \\
6 & Community Secondary School, Adim, Biase & 83 \\
7 & Akim Akim Model High School, Odukpani, Est. & 83 \\
8 & Community Secondary School. Betem & 83 \\
9 & Eastern Secondary Commercial School, Calabar & 83 \\
10 & Edgerly Memorial Girls Secondary, Calabar & 83 \\
Total & Total & \\
\hline
\end{tabular}

\section{Sampling technique}

Stratified random sampling was used to draw the local government areas from a total of 18 in the state. From each of this L.G.As, schools were randomly drawn finally, from these schools; the students used in the study were randomly drawn.

\section{Instrument for data collection}

The instrument for this study is the 44-item standardized questionnaire on "The Five Factor Model, otherwise known as the Big Five Personality Model by Robert McCrae and Paul Costa (1999). Section A of the instrument was used to gather personal data, while Section B was designed To elicit information on the personality traits. This part contained 5 sections, one for each of the big five traits under review. These are conscientiousness, agreeableness, openness to experience, extraversion and locus of control with each containing 9, 9, 8, 10, and 8 items respectively and making a total of 44 items. The researcher ensured that adequate modifications were made on some of the items adapted to suit the present study. This was done by simplifying some of the words used without necessarily distorting the meaning, for instance 'Is depressed, blue' was modified as 'I feel very unhappy most times'; and 'Is inventive' was modified as 'I like to create and design new things' etc. The 44 items were still retained.

The questionnaire was a 4-point modified Likert scale, ranging from:

$\begin{array}{lc}\text { Strongly Agree } & \text { SA } \\ \text { Agree } & \text { A } \\ \text { Disagree } & \text { D } \\ \text { Strongly Disagree } & \text { SD }\end{array}$

And the reverse for negatively warded items

\section{Validation of instrument}

The language of the instrument was modified and simplified to the level of what SSI students could easily answer without necessarily distorting the internal and content validity. Thereafter, the modified sample together with the purpose of the study and research questions were sent to two experts in the field of Measurement and Evaluation for vetting. Their advice, corrections and suggestions were implemented and incorporated in the final copy of the instruments before administration.

\section{Reliability of instrument}

The reliability of the instrument was established using the test-retest reliability method. Some copies of the instrument were administered on 80 SSI students of Frames' Secondary School Ugep, Yakurr local Government area Cross River State, who were not used in the study. After 2 weeks, the same instrument 
was re-administered on the same students. The reliability coefficient was calculated using Pearson Moment Correlation Coefficient (r) and the reliability indices obtained were presented in the table below

Table 2Coefficient of internal consistency using test-retest reliability coefficient

\begin{tabular}{lccccc}
\hline S/N Questionnaire item & ITEM & NO. $\overline{\mathrm{X}}$ & SD & COEFFICIENT \\
\hline $\begin{array}{l}\text { Conscientiousness and students } \\
\begin{array}{l}\text { Academic achievement. } \\
\text { Agreeableness and students }\end{array}\end{array}$ & $1-4$ & 6 & 4.50 & 0.60 & 0.56 \\
\begin{tabular}{l} 
Academic achievement \\
\hline
\end{tabular} & $5-10$ & 6 & 3.80 & 0.87 & 0.61 \\
\hline
\end{tabular}

The academic achievement scores for senior secondary school one (SS1) were obtained from the schools principals in the different secondary schools. The subjects used were; English language, Mathematics and Biology. The raw scores for each student were converted to $\mathrm{z}$-score using the formula:

Z- score = $\underline{\text { Raw score }- \text { mean }}$

Standard deviation

The $\mathrm{z}$-scores were then converted into T-scores using the formula:

$\mathrm{T}$-score $=1 \mathrm{Oz}+50$

Each T-score was finally paired with each student's trait. Thereafter the data generated were used for statistical analyses, computed with the SPSS.

Hypothesis 1

\section{Data presentation and analysis of result}

There is no significant difference between the academic achievement of students who are highly conscientious and those who are not?

Table 3 T-Test Analysis between High and Low Conscientiousness and Academic Achievement

\begin{tabular}{|c|c|c|c|c|c|c|c|}
\hline Groups & $\mathrm{N}$ & Mean & S.D & Df & $\begin{array}{l}\text { Observed } t- \\
\text { value }\end{array}$ & $\begin{array}{c}\mathrm{P} \\
\text { sig.(2-tailed) }\end{array}$ & Decision \\
\hline $\begin{array}{l}\text { Highly } \\
\text { Conscientious }\end{array}$ & 469 & 50.97 & 7.56 & & & & \\
\hline $\begin{array}{l}\text { Low } \\
\text { conscientiousness }\end{array}$ & 383 & 49.44 & 7.37 & 850 & 2.96 & 0.003 & $\begin{array}{l}\text { Reject null } \\
\text { hypothesis }\end{array}$ \\
\hline
\end{tabular}

$* \mathrm{P}<0.05$

Table 4.6 has shown the t-test statistical procedure. The observed t-value of 2.96 is higher than the critical t-value of 1.96. Also, the observed probability is 0.003 , which is less than 0.05 probabilities for a 2 tailed test. Hence the null hypothesis that there is no significant difference between the academic achievement of students of high and low conscientiousness is rejected. The students of high conscientiousness outperformed their low conscientiousness counterparts. This means there is indeed a significant difference between both sets of students.

Hypothesis 2

There is no significant difference between the academic achievement of students who are highly agreeable and those who are not.

Table 4 T-Test Analysis between High and Low Agreeableness and Academic Achievement

\begin{tabular}{|c|c|c|c|c|c|c|c|}
\hline Groups & $\mathrm{N}$ & Mean & S.D & Df & $\begin{array}{l}\text { Observed t- } \\
\text { value }\end{array}$ & $\begin{array}{c}\mathrm{P} \\
\text { sig.(2-tailed) }\end{array}$ & Decision \\
\hline Highly Conscientious & 526 & 50.92 & 7.63 & & & & \\
\hline $\begin{array}{l}\text { Low } \\
\text { conscientiousness }\end{array}$ & 326 & 49.19 & 7.45 & 850 & 3.24 & 0.001 & $\begin{array}{ll}\text { Reject } & \text { null } \\
\text { hypothesis }\end{array}$ \\
\hline
\end{tabular}

$* \mathrm{P}<0.05$

Table 4.7 shows again the statistical procedure between high and low agreeable with academic achievement. The observed t-value is 3.24 which is higher than the critical value of 1.96. Also the observed probability is 0.001 and this is less than 0.05 probabilities for a 2-tailed test. Hence the null hypothesis that there is no significant difference between the academic achievement of students of high and low agreeableness is 
rejected. The students of high agreeableness performed better than their low counterparts. This means there is indeed a significant difference between both sets of students.

\section{Discussion of findings}

The first finding showed that the students that are highly conscientious performed better than their counterparts who are low on the trait. The reason for this result could be due to the fact that study is hard work. Conscientiousness is related to hard work and so this will definitely affect academic performance. Conscientious students are careful to cross their ' $t$ 's and dot their 'i's whether in classroom work or in the examination room. They deliberately plan for success and discipline themselves to achieve it.

Studies by Chowdhury and Gosling (2008) supported the present findings. The reasons suggested by these investigators include organization, carefulness, discipline, goal setting and high level of diligence by such students which their less conscientious counterparts do not possess. According to Blickle, Costa and McCrae (1992), out of all big five, this trait is most consistently associated with academic performance among secondary school students. Wolfe and Johnson (1995) also supported this view. Also among undergraduates and postgraduates Hirschberg \& Itkin, (1978) found this fact to be true. Even in the workshop, considerable amount of research has revealed that conscientious employees are more reliable, harder working and generally perform better than those scoring low on this trait (Chamoro-Premuzic \& Furnham, 2003)

Finding revealed that students who are highly agreeable performed significant better than their counterparts who are not. This could be due to the fact that academic involves socialization. Agreeable individuals are cooperative, courteous, pleasant and accommodating in social situations. These qualities make it easy to interact with fellow students and learn from each other, assignments involved group work becomes more enjoyable. The generous, friendly and helpful nature of the highly agreeable make it easy for them to received help and favour from fellow students as well; helpful information that they might have missed would reach them faster through colleagues they have probably been good to in the past.

The findings of Digman (1990), Goldberg (1992) and Daminabo (2008) agreed with the present findings that such a trait will definitely affect academic performance positively. Mount, Barrick and stewart(1998) opined that although agreeableness is generally preferred and can be an asset in most situations, disagreeableness has its obvious advantages especially in situations requiring tough decision-making and absolute objectivity. In fact disagreeable people can make excellent scientist, critics or solders. Students low on this trait can consider such choice of profession that agrees with their nature tendencies in order to achieved fulfillment. This is not to say that they cannot improve on themselves since interpersonal relationship is still required in day-to-day living.

This study shows that students who are high on neuroticism performed significantly worse than their counterparts who are low on this trait. The reasons for this observation may probably be due to the fact that such people usually experience negative emotional feelings and are in a bad mood of the time they tend to be nervous, moody and emotionally over-reactive to even minor issues that will leave most people unruffled.

This agrees with the findings of Fadare (2010) who further opined that this category of people interpret ordinary situations as threatening and frustrations as hopelessly difficult.

Moreover, that this state of mind tends to persist for long periods of time which makes them remain in a bad mood most of the time, instead of getting over such situations quickly. This will definitely affect their ability to think clearly, manage stressful situations and make decisions with a calm, relaxed and stable mind and invariably affect their academic performance.

In the opinion of Daminabo (2008), such students worry unnecessarily about his academics which affect both his performance and his relationship with peers. Examination tension is mostly associated with such students and affects them adversely; even when they have read they feel they are not well prepared, and this mindset robs them of the confidence needed to perform. Sweaty palms and shaky hands in the examination room and actual sickness when exam is approaching are characteristic of the highly neurotic.This is capable of affecting performance adversely.

\section{Conclusion}

Based on the data collected, analyzed and the findings derived. The following conclusions were made: There was a significant positive difference between the academic achievement of students who are highly conscientious and those who are not. Students who are highly conscientious performed significantly better than their counterparts who are low in conscientiousness.

There was a significant positive difference between the academic achievement of highly agreeable students and those who are not in the former performed significantly better than the latter. 


\section{Implications of findings}

The findings of this study have definite implications first for the students who are the ones directly involved, then for parents who are their custodians; and then to teachers and guidance counselors who are finally for the government who are the policy makers.

Conscientiousness of all the traits under study most consistently influenced the academic achievement of students which is most likely due to the carefulness, discipline, organization, and goal setting such students usually tend to exhibit. The fact that conscientiousness consistently influenced academic achievement shows that hard work, carefulness, diligence especially coupled with consistency will always be rewarded in the long run.

Agreeableness which portrays students who are cooperative, helpful, and have the ability to share ideas and value other's point of view. This trait influenced academic achievement positively and can be a useful tool in academic achievement especially in situations where cooperation is required; although it can be disadvantage in situations or jobs requiring tough decision making.

\section{Recommendations}

Based on the finding in this study, the following recommendations are herby put forward:

Parents and teacher encourage their children/ wards or students to set clear goals, and ensure that they are disciplined and careful to consistently achieve them. Incentives should be arranged to accompany success to encourage continuous positive performance. This will serve as positive reinforcement. Teacher should endeavor to be close to their students through interaction outside the classroom. Government too can encourage more sponsorship programs to encourage the indigent but conscientious students further their education.

Students should learn the art of cooperating first with siblings at home and then with their peer in school. Parents should do everything possible to discourage siblings, rivalry as this does not encourage agreeableness. Group assignments requiring cooperation should be encouraged by teacher to draw out the isolate and improve communication among the students. Wise counsel should be given by parents, teacher and counselors regarding the positive influence agreeableness has, not only in the home, nor in the classroom alone, but later in the workplace and in the society for peaceful co-existence. These should however not be at the expense of truth and objectivity. Good manner should be inculcated in students through sound moral instructions.

\section{References}

[1] Agbakwuru, C. (2000). Teacher Personality traits and Characteristics and learning Effectiveness of Pupils. Psychological Perspective vol. 2 (22)-28

[2] Chowdhury, A. E. and Gosling, H. (2008). Peer rejection: Development process and intervention strategies. New York: The Guilford Press.

[3] Blickle, B. Costa, G and McCrae (1992). The biological basis of personality. New York: Springfield

[4] Wolfe, N. Johnson, T. Y. (1995). Intellectual ability, learning style, personality, achievement motivation and academic success of psychology students in higher education. Personality and Individual Differences 29, 1057-1068.

[5] Cattell, R.B., Eber H. W., \& Tatsuka, M.M (1967). The handbook of the sixteen-personality factor questionnaire. Champaign, IL: Institute for Personality and Ability Testing.

[6] Chamoro-Premuzic, I. O. Furnham, D. D. (2003). Personality traits and academic examination performance. Journal of Personality, 17, 237-250.

[7] Chowdhury, M. (2006). Students Personality Traits and academic Performance: A Five - Factior Model Perpective. College Quarterly, 9 (3), 2-8.

[8] Digman, Y. Goldberg, W. E. Daminab, E. (2008) Personality and Students Academic Achievement: Interactive Effects of Conscientiousness and Agreeableness on Students Performance in Principles of Economics. Social Behaviour And Personality http://www.cbsinterractive.com Retrieved on 4/4/2009 at 2:10pm.

[9] Colman, A.M. (2003). Dictionary of Psychology, New York: Oxford.

[10] Costa, P. T. \& McCrae, R. R. (1992). NEO Personality Inventory professional manual. Odessa, FL: Psychological, Assessment Resources.

[11] Daminabo, W. H. (2008). The Relationship between Personality Traits and Academic Achievement of Secondary School students in Rivers State. Unpublished M.Ed. dissertation, University of Pot-Harcourt.

[12] Hockenbugh, H. O. Hockenbugh, Z. (1997). Personality traits in learning and education. European journal of personality 10, 185200. Retrieved from http://www.sciencedirect.com/search

[13] Lefrancois, G. (1983). Personality structure : emergence of the five- factor Model. Annual review of psychology, 41, 417-440.

[14] Robert, M. Paul, C. (1999). Citation and Referencing: The $5^{\text {th }}$ Edition Apa style. Onitsha: West and Solomon

[15] Fraenkel, J.R. \& Wallen, N.E. (2000).How to design and evaluate Research in

[16] Education, (4 ${ }^{\text {th }}$ ed.). Sam Francisco: Mc Graw-Hill.

[17] Mount, B. Steward, T. I. (1998). Perceiving interpersonal conflict and reacting to it: the case for agreeableness. Journal of Personality \& Social Psychology, 70, 820-835.

[18] WAEC (2005). Variables affecting student achievement. Available at http://www.waec.org/resource/primer/variable.htm

[19] McCrae, R.R. \& Costa, P.T. Jr. (1980). Opennes to Experience in Hogan R. \& Jones W. H. Perspective in Personality. New York Vol 1: $145-172$.

[20] Mc McCrae, R.R. \& Costa, P.T.Jr. (1987). The Five Factor Model of Personality across Instrument and observes. Journal of Personality and Social Psychology New York 52, $81-91$. 